\title{
Fracture mechanisms and size effects of brittle metallic foams: In situ compression tests inside SEM
}

\author{
Hong-Wei Song a,b,*, Qi-Jian He ${ }^{\mathrm{a}}$, Ji-Jia Xie ${ }^{\mathrm{b}}, \mathrm{A}$. Tobota ${ }^{\mathrm{c}}$ \\ anstitute of Mechanics, Chinese Academy of Sciences, Beijing 100190, PR China \\ ${ }^{\mathrm{b}}$ State Key Laboratory of Nonlinear Mechanics, LNM, Institute of Mechanics, Chinese Academy of Sciences, Beijing 100190, PR China \\ ${ }^{\mathrm{c}}$ Institute of Production Engineering and Automation, Mechanical Engineering Faculty, Wroctaw University of Technology, Poland
}

\section{A R T I C L E I N F O}

\section{Article history:}

Received 26 November 2007

Received in revised form 13 April 2008

Accepted 17 April 2008

Available online 1 May 2008

\section{Keywords:}

A. Metallic foams

B. Mechanical properties

B. Stress/strain curves

C. Deformation

D. Scanning electron microscopy (SEM)

\begin{abstract}
A B S T R A C T
In situ compressive tests on specially designed small samples made from brittle metallic foams were accomplished in a loading device equipped in the scanning electron microscopy (SEM). Each of the small samples comprises only several cells in the effective test zone (ETZ), with one major cell in the middle. In such a system one can not only obtain sequential collapse-process images of a single cell and its cell walls with high resolution, but also correlate the detailed failure behaviour of the cell walls with the stressstrain response, therefore reveal the mechanisms of energy absorption in the mesoscopic scale. Meanwhile, the stress-strain behaviour is quite different from that of bulk foams in dimensions of enough large, indicating a strong size effect. According to the in situ observations, four failure modes in the cell-wall level were summarized, and these modes account for the mesoscopic mechanisms of energy absorption. Paralleled compression tests on bulk samples were also carried out, and it is found that both fracturing of a single cell and developing of fracture bands are defect-directed or weakness-directed processes. The mechanical properties of the brittle aluminum foams obtained from the present tests agree well with the size effect model for ductile cellular solids proposed by Onck et al.
\end{abstract}

(c) 2008 Elsevier Ltd. All rights reserved.

\section{Introduction}

Metallic foams, especially those made from aluminium and its alloys, have received a significant increase of interest in the past few years. An important application of such ultralight foam is serving as crashworthy component, such as fillers in the tubular structures [1-6] and cores in the laminated sandwiches [7-11]. In addition to the lightweight and high specific energy absorption (energy absorbed per unit weight), the low strengths and large plastic strains, which usually mean attenuated acceleration and elongated crushing distance during an impact event, make foams very attractive for energy absorbing applications.

In general a metallic foam can be characterized on three scales [12-20]: the microscopic scale, which mainly deals with microstructures in cell walls; the mesoscopic scale, which mainly deals with the morphology, deformation and fracture in the cell and cell-wall level; and the macroscopic scale, which mainly deals with the collapse behaviour (e.g., deformation bands) and mechanical properties in the bulk-foam level. Gibson and Ashby [12] pointed out that although mechanical properties of metallic foams do concern with the micro and meso structure, the related parameters are

\footnotetext{
* Corresponding author. Address: Institute of Mechanics, Chinese Academy of Sciences, Beijing 100190, PR China. Tel.: +86 01082544149.

E-mail addresses: songhw@imech.ac.cn, songhw@tsinghua.edu.cn (H.-W. Song).
}

difficult to be expressed in analytical models and impracticably to be checked once in use. It is perhaps for this reason that most early works focused on the macroscopic aspects. However, characterization the role of meso and micro structures during deformation is very important, since the amount of energy absorbed is directly related to the way the cell structure fails or collapses $[17,20]$. Two major approaches can be classified in the recent surge in characterizing the micro and meso structure of cellular solids: scanning electron microscope (SEM) and X-ray tomography. Markaki and Clyne [16] examined cell wall microstructures of three different closed-cell Al alloy foams in SEM, and found that the microstructures can substantially affect the deformation and failure behaviour of metallic foams. When studying the mechanics of compressive deformation in open-cell Al foams, Zhou et al. [21] employed an ex situ SEM technique: after each loading-unloading cycle, the tested sample was moved to SEM and examined. However, application of this method to the brittle metallic foams may be difficult, since the cell walls collapse into fractured debris and can hardly maintain integrity once unloaded and moved. Motz and Pippan [22], in a real sense, performed in situ tests in scanning electron microscope. They carried out standard fracture toughness tests on compact tension of ductile metallic foams, and find that the deformation is strongly localized to the thinnest parts of the cell wall, where cracks initiate and propagate. Usually the nondestructive imaging of collapse behaviour of metallic foams rely 
on surface observation. As a powerful tool, X-ray tomography is recently adopted to acquire the mesoscopic structures from three dimensions [17,18,20,23]. Maire et al. [17,23] acquired 3D numerical images by high resolution X-ray tomography to study the microstructure and also the damage of different cellular materials. They also examined several method of finite element modeling based on the acquired images. Elmoutaouakkil et al. [18] quantitatively characterized the cellular morphology of metallic foams in terms of cell size/volume distribution, cell wall thickness distribution, with the help of X-ray microtomography. McDonald et al. [20] employed the same method to collect three-dimensional images of aluminum closed-cell foam from the in situ compressive deformation experiment, and suggested not only the position of large cell volumes to be very important in the local concentration of stress, but also the distribution of cell volumes of immediate neighbours.

Size effect is another important issue in the mechanical testing of cellular solids. Size effect means, the specimen size relative to the cell size has great influence on the measured properties. The size effect is also very important in the design and application of foam component, e.g., the thickness of the foam core may greatly influence the overall performance of the sandwich panel. The size effect of a unconstrained or bare metallic foam and that of constrained foam (e.g. the core foam for sandwich panels) is quite different however [9,24-29]. For a bare foam column, when the specimen size relative to the cell size decreases, the fraction of stress-free cells at the surfaces increases and the constraint of the cell walls at the boundary becomes weaker, both effects lead to decreased moduli and strengths [24,26].

In this paper, in situ compression tests for specially designed AlSi alloy foam samples were accomplished inside a scanning electron microscopy with a small loading device, and high resolution images of cell morphology evolution and compressive load vs. displacement curves were acquired simultaneously. The aims of this unconventional method lie in two aspects: (1) to inspect how does the deformation and failure process of a single cell and cell walls influence the stress-strain response, therefore identify the main energy absorption mechanisms; (2) to examine the size effect arisen in this specific loading condition. Conventionally the bulk foam specimens used in the uniaxial compression tests are in dimensions of over 10 times the cell size, and the measured stress-strains represent the overall collapse responses of multiple cells. In the present study, the effective test zone (ETZ) of the specially designed samples is in a dimension of only 1-2 cell diameters, therefore the stress-strain responses can be conveniently explained by the corresponding mesoscopic failure mechanisms. Parallel to the mesoscopic tests, macroscopic compression tests on bulk foams were also carried out. Special attention was given to the relationship of cell wall fracture in the single cell and the formation of fracture bands in the bulk foam. Since the tests demonstrate a strong size effect, the mechanical properties obtained from the mesoscopic and macroscopic tests were correlated with the size-effect models proposed by Onck et al. [24].

\section{Experimental procedures}

\subsection{Material characterization}

The AlSi12 closed-cell foams, provided by Shenyang NEU Advanced Materials Development Co. Ltd. of China, were used in the present study. The NEU foams were produced by molten body transitional foaming process with several steps [30]: (i) melting alloy of aluminum silicon and calcium in furnace; (ii) adding titanium hydride ( $\mathrm{TiH} 2$ ) to the molten body; (iii) transferring the molten body to the bubbling case; (iv) pushing the bubbling case to the maintaining furnace and foaming in it; and ( $\mathrm{v}$ ) post process- ing. No obvious directional effect is found and the NEU foams. The AlSi12 foams have been demonstrated as typical brittle materials. San Marchi et al. [19] reported that the elongation to failure $e_{\mathrm{f}}$ for the AlSi12 foams is between $1 \%$ and $2 \%$, by contrast the pure Al foams display $e_{\mathrm{f}}>5 \%$. The apparent density of the foams is about $0.67 \mathrm{~g} / \mathrm{cm}^{3}$ and the relative density is about 0.25 . Distribution of cell sizes was obtained with the Image-Pro system by counting of 550 cells on the surfaces of a typical sample, as illustrated in Fig. 1. The "cell size" for a single cell is defined as

$\bar{D}=\frac{1}{n} \sum_{i=1}^{n} D_{i}(i \theta)$

where $D_{i}(\theta)$ is the $i$ th "diameter" passing through the cell's centroid measured at $\theta$ degree intervals, $n$ is the number of such "diameters" and $n=\operatorname{int}\{180 / \theta\}$. Here $\theta$ takes $2^{\circ}$, therefore the cell size was taken as the mean value of 90 "diameters", measured at $2^{\circ}$ intervals. In Fig. 1, the left and right vertical axis are number fraction and area fraction of a specific cell size, respectively. The largest number fraction is found in cell size below $0.5 \mathrm{~mm}$, indicating many pores in the cell walls. According to the area fraction, the average cell size $d$ can be taken as $3 \mathrm{~mm}$ for the foams.

\subsection{In situ mesoscopic compression tests}

Specially designed dog-bone specimens were examined in the mesoscopic compression tests. The specimen geometry is shown in Fig. 2. The effective test zone (ETZ) is in dimensions $4 \mathrm{~mm} \times 6 \mathrm{~mm} \times 4.5 \mathrm{~mm}$. Upon loading, the stress level inside the ETZ would be significantly higher than that of outside ETZ, due to the narrowed width. The shape and dimensions guarantee that collapse initiates and progresses within the ETZ and can be observed directly in the SEM. The adopted dimensions are also partially due to the restricted space inside the SEM, as well as the limitation of the loading cell. Samples were carefully selected from the raw foam material to make sure that one "complete" cell located at the center of ETZ, and then were sectioned by electro-discharge machining (EDM) to avoid local damage to the cell walls. To minimize contaminants, the samples were first washed in the coal oil and then subjected to ultrasonic cleaning in the acetone solution before being tested. Uniaxial compression tests for the mesoscopic samples were carried out in a small loading device, which was equipped inside the S570 SEM. The experimental set-up is illustrated in Fig. 3. Samples were compressed at a cross-head speed of $0.2 \mathrm{~mm} / \mathrm{min}$ (some were compressed at a speed of $0.08 \mathrm{~mm} / \mathrm{min}$ ), to a deformation of $4 \mathrm{~mm}$ (which equals to the

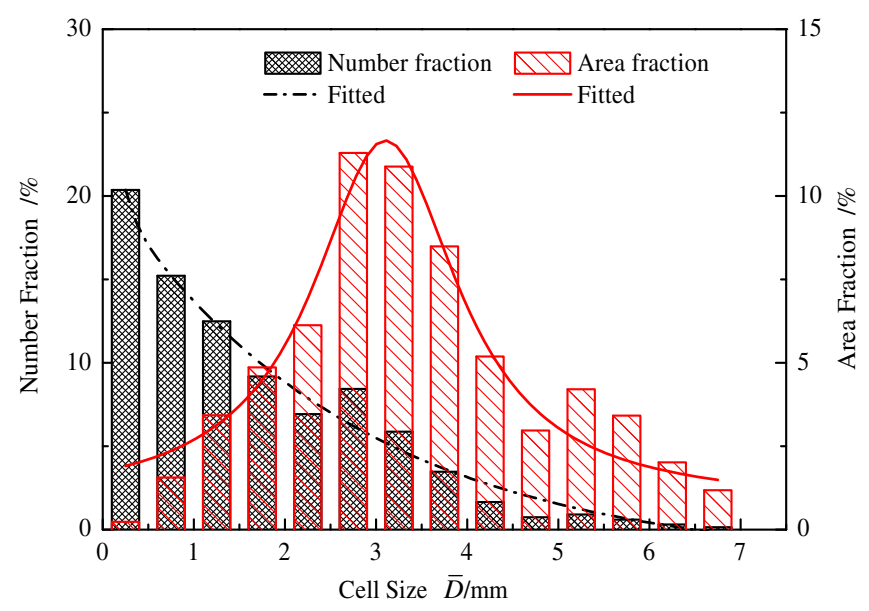

Fig. 1. Distribution of cell sizes. 


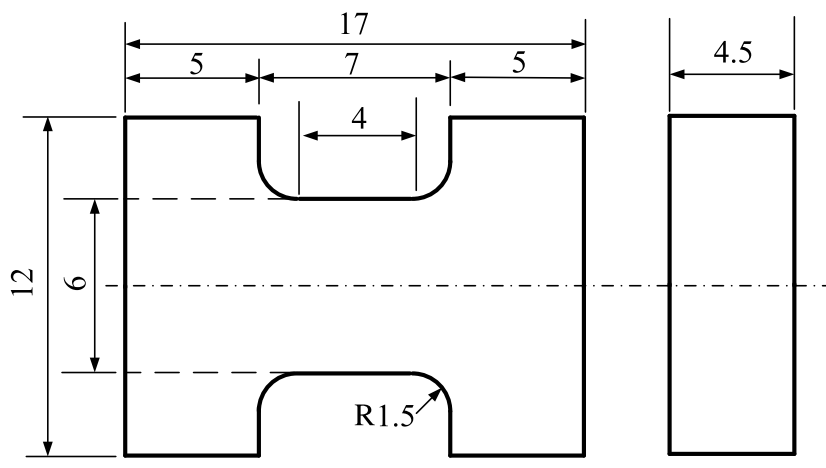

Fig. 2. Dog-bone specimen for in situ mesoscopic compression tests in the SEM.

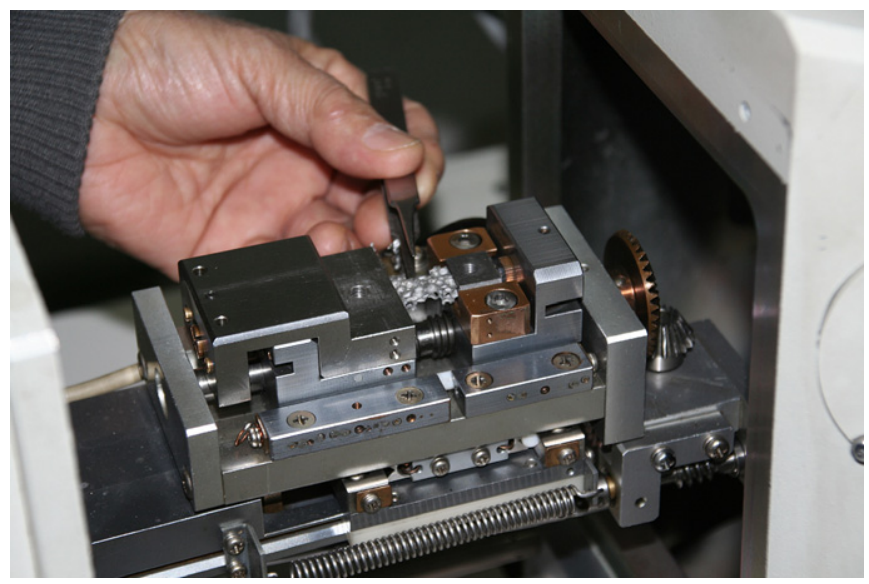

Fig. 3. Loading device with a sample to be furnished inside the SEM.

length of ETZ, indicating an apparent engineering strain $\varepsilon_{\mathrm{E}}$ of $\left.100 \%\right)$. Load and displacement data were sampled and processed in a personal computer. Series images for the cell deformation were acquired in the SEM at an interval of every $5 \%$ deformation.

\subsection{Macroscopic compression tests}

Square prism samples in dimensions $45 \mathrm{~mm} \times 45 \mathrm{~mm} \times 60 \mathrm{~mm}$ were sectioned from the raw foam material via EDM. Each edge is at least 15 times of the average cell size $d$, in order to minimize the size effect and obtain the representative properties. The faces were slightly polished with fine sands to improve the contrast between the cell wall and the non-wall regions. Uniaxial compression tests on the bulk samples were carried out in an MTS servo-hydraulic testing machine equipped with a $10 \mathrm{kN}$ load cell. All the samples were tested in the displacement-controlled mode with a crosshead speed of $2 \mathrm{~mm} / \mathrm{min}$, till $80 \%$ deformation was achieved. Digital images of two opposite faces were acquired at $10 \mathrm{~s}$ intervals with a charge-coupled device (CCD) camera connected with Qustar system and a Cannon 350D DSLR camera respectively. The resolution of the images are $768 \times 576$ and $3456 \times 2304$ pixels respectively.

\section{Results}

\subsection{Fracture process of cell walls and stress-strain responses}

Altogether six mesoscopic samples were tested. Since ETZ dimension is within two times the cell size, local imperfections and variance in cell morphology (cell shape, cell size and cell wall thickness, etc.) would dominate the compression behaviour, therefore a significant difference in the stress-strain responses could be expected. This discrepancy does not matter much, since the main purpose of the tests is to correlate the fracture process of cell walls with the stress-strain responses, therefore reveal the mechanisms of energy absorption. Fig. 4 gives some of the stress-strain curves obtained from the mesoscopic tests. One can still find some common items, e.g., each of the crushing histories can be roughly divided into three stages. We will focus in a typical mesoscopic test in the following section.

In Fig. 5, the effective test zone (ETZ) was extracted from the low magnification SEM image of a representative untested sample. The morphology of ETZ needs to be characterized first. A "complete" cell, marked $\Omega$, is located at the center of the ETZ. The cell $\Omega$ can be viewed as being composed of six cell walls, numbered

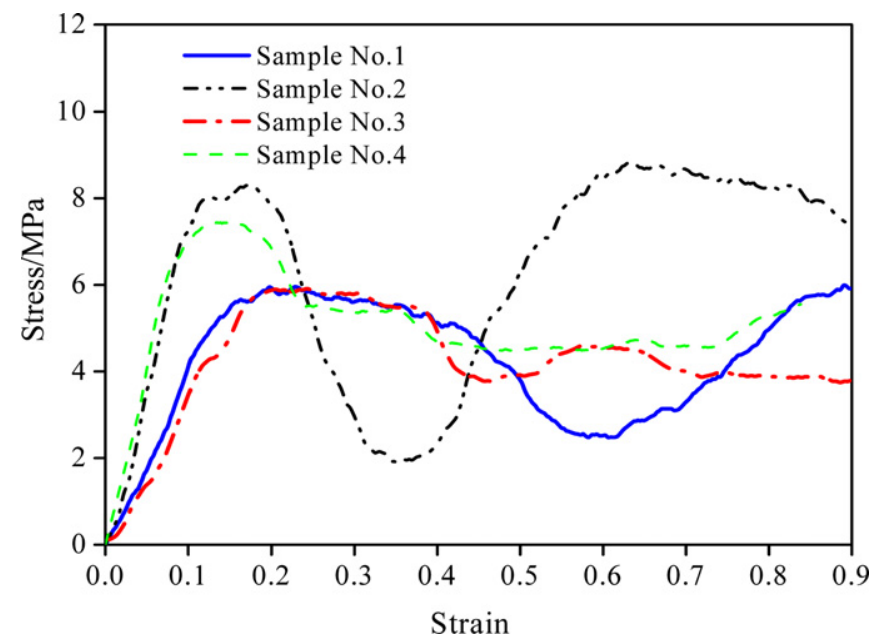

Fig. 4. Discrepancies in stress-strain curves in mesoscopic compression tests.

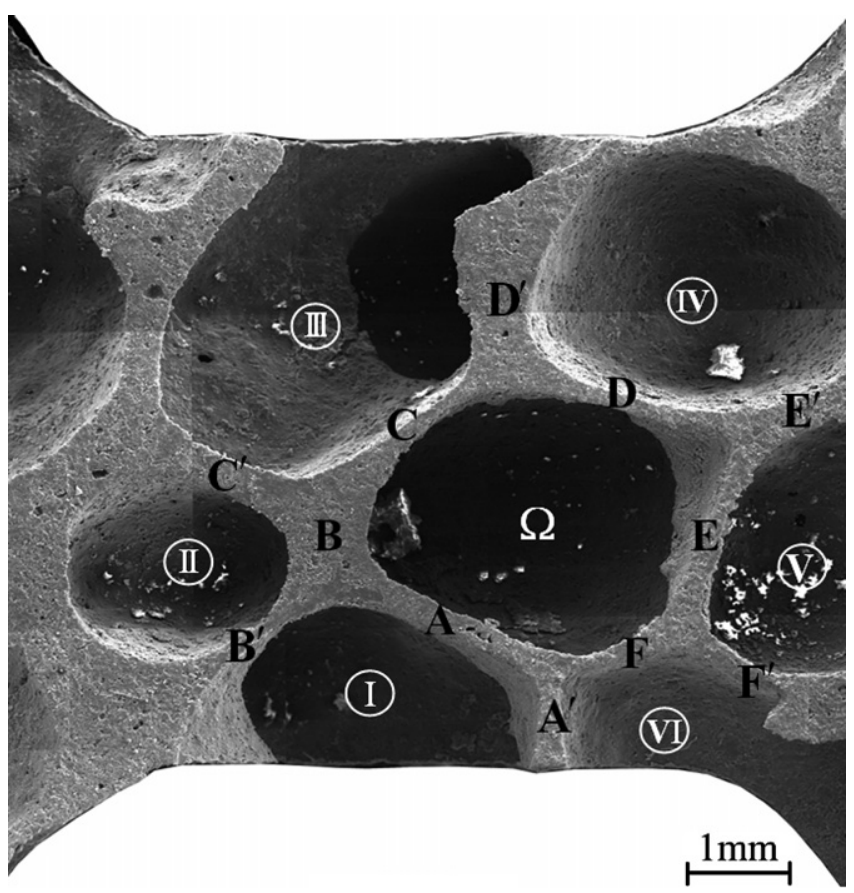

Fig. 5. Characterizing the ETZ of a representative sample before compression test $\left(\varepsilon_{\mathrm{E}}=0\right)$. Special attention is given to cell $\Omega$, cell walls and struts of $\Omega$ are numbered from A to $F$ and $A^{\prime}$ to $F^{\prime}$ in the clockwise, respectively and cells surrounding $\Omega$ are numbered from I to VI in the clockwise. Obvious defects are spotted in cell wall A. 
from A to $\mathrm{F}$ in the clockwise. Meanwhile, $\Omega$ is surround by six neighbouring cells, either "complete" or "incomplete" in shape, numbered from I to VI in the clockwise. Each of the neighbouring cell shares one common cell wall with $\Omega$. The cell $\Omega$ is also supported by 6 struts, which are the cell walls of the surrounding cells. The struts are numbered from $\mathrm{A}^{\prime}$ to $\mathrm{F}^{\prime}$ in the clockwise, in corresponding to the cell walls which compose $\Omega$.

Unlike common ductile, solid metals which have significant Poisson's effect, in compression the plastic Poisson's ratio of the metallic foams is very small and even can be taken as zero $[6,13,22,31,32]$, hence the true stress-strain can be approximated by the engineering stress-strain. In Fig. 6, the nominal stressstrain curves were obtained by dividing the applied load by the original cross-sectional area of ETZ to obtain the stress, and dividing the measured displacement by the original ETZ length to obtain the strain. Refer to Fig. 6, the characteristic deformation and fracture process of cell walls, together with the stress-strain responses, will be described in details according to the loading stages.

Stage $0\left(\varepsilon_{\mathrm{E}}=0 \%\right)$ : The initial stage can be referred to Fig. 5 . The morphology and location of cells gives a basic clue for the first collapse. Cells I, III and VI, located at the edges of the sample, demonstrate pronounced edge effect: they provide less mechanical support upon loading and the stress level is relatively low [20,24,25]. Cells II, IV and V, however, located partially inside ETZ and partially outside. Collapse in these cells at the initial loading stage is less likely, since lower stress level would be achieved outside ETZ. Comparably, stress concentration in the cell $\Omega$ is predominant, due to its location inside ETZ and the relatively thin cell walls.

Stage $1\left(\varepsilon_{\mathrm{E}}=10 \%\right)$ : Compressive stress increased with increasing strain almost linearly till an apparent large strain 10\%, accompanied by the overall elastic deformation of the cell walls. Notice that cell walls outside ETZ also experienced elastic deformation at this stage, therefore, the elastic strain calculated with the method mentioned in the early part of this section is significantly larger than that is real. At the final stage of elastic deformation, cell wall $\mathrm{A}$ yielded. As being analyzed in the previous stage, stress concentration would take effect in cell $\Omega$. The obvious defects in the cell wall A induced further local stress concentration and weakened the wall strength. As a result, the first yield took place in cell wall $\mathrm{A}$.

Stage $2\left(\varepsilon_{\mathrm{E}}=15 \%\right)$ : Cell wall A failed in bending fracture, forming three "hinges". The fractured cell wall segments moved around the "hinges" under the bending moment induced by remote compressive stress. This phenomenon is similar to "plastic hinges" in the axial crushing of thin-walled ductile metal tubes, except that in the present situation the "hinges" are not plastic but brittle fractured. Cell wall $C$ begun to yield, due to the stress redistribution after cell wall A fracture. The stress level is appreciably high at this stage, and both fracturing of wall A and yielding of wall C contribute to this high stress.

Stage $3\left(\varepsilon_{\mathrm{E}}=20 \%\right)$ : Cell wall $\mathrm{C}$ failed in bending fracture, forming two "hinges". No obvious damage was found in other cell walls. At this stage cell wall A fractured into discontinuous fragments which sustain little load. Correspondingly, the stress begun to drop.

Stage $4\left(\varepsilon_{\mathrm{E}}=30 \%\right)$ : Cell walls $\mathrm{A}$ and $\mathrm{C}$ lost integrity and constraint, leaving the undamaged cell walls move in a manner of rigid body. The stress dropt significantly. Visible crack initiated in the cell wall $\mathrm{E}$ under the tensile stress induced by remote compression. By the end of this stage, all the damaged and fractured cell walls belong to $\Omega$. Cells I, III and $\Omega$ are the only three cells collapsed.

Stage $5\left(\varepsilon_{\mathrm{E}}=35 \%\right)$ : Cell wall E fractured, and crack initiated in cell wall $\mathrm{F}^{\prime}$, forming the first damage in a cell wall that is outside $\Omega$. At this stage, cell $\Omega$ as well as cells I and III were seriously damaged and sustained little stress, and stress concentration begun to transfer to other cells. As a result, a trough stress value arrived.
Stage $6\left(\varepsilon_{\mathrm{E}}=40 \%\right)$ : Cell walls $\mathrm{F}, \mathrm{F}^{\prime}$ and $\mathrm{A}^{\prime}$ fractured and lost integrity. The fractured fragments tended to be compacted, causing a notable increase in stress in the subsequent stages.

Stage $7\left(\varepsilon_{\mathrm{E}}=50 \%\right)$ : Two opposing cell walls in III, $\mathrm{D}^{\prime}$ and $\mathrm{D}^{\prime \prime}$, begun to contact, indicating a further compaction. The stress increased continuously.

Stage $8\left(\varepsilon_{\mathrm{E}}=60 \%\right)$ : $\mathrm{D}^{\prime}$ and $\mathrm{D}^{\prime \prime}$ contacted each other in two areas. The broken cell walls and fractured region have been sufficiently compacted, as an indicator the stress rise to a level near maximum. At this stage, only three undamaged or partially damaged cells inside ETZ can be distinguished.

Stage $9\left(\varepsilon_{\mathrm{E}}=75 \%\right)$ : The debris fractured $\mathrm{D}^{\prime \prime}$, a cell wall that is outside ETZ. This indicated the end of the mesoscopic compression test, and the stress-strain thereafter should not be taken as "real".

At the final stage (refer to stage 8), 4 out 6 cell walls of $\Omega$, i.e., A, C, E, and F fractured. By contrast, only two cell walls $\left(A^{\prime}\right.$ and $\mathrm{F}^{\prime}$ ) outside $\Omega$ fractured. The fracturing of cell walls belong to the neighbouring cells leads to a stress redistribution and fracture region evolution. A small collapse path (or collapse band) is formed and this path is not perpendicular to the loading direction. Apparently, cracks and fractures follow the weakest path throughout the cell structure, therefore the fracture process is weakness and defects directed one. A typical stress-strain curve obtained from mesoscopic compression tests can be divided into three regimes: elastic regime, bending and fracturing regime, and densification regime. Unlike the bulk foams which have a plateau stress regime, in meso tests the stress in the bending and fracturing regime is not stable, since the local failure significantly affects the stress response in such small dimensions. Meanwhile, the densification effect is not as obvious, again due to the edge effect.

\subsection{Macroscopic collapse behaviour of the foam}

Altogether five macroscopic samples were tested. Fig. 7 gives the typical stress-strain responses and several characteristic images of bulk foam under compression. Similar to the common metallic foams, the typical stress-strain curve of the AlSi brittle foam can be divided into three regimes [15,33]: elastic regime, where the compressive stress increases with increasing strain almost linearly, accompanied by the overall elastic deflection of

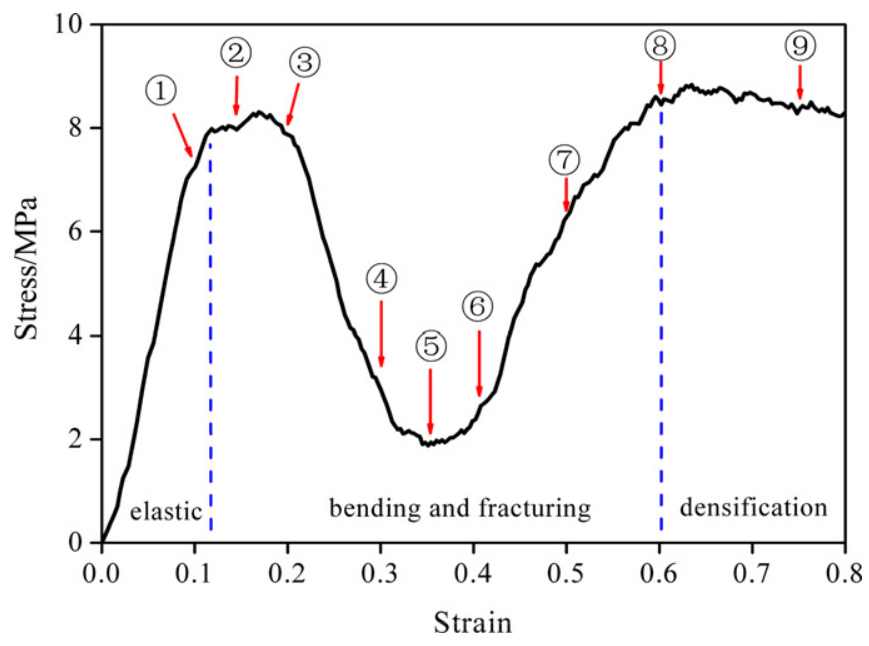

Fig. 6. Deformation and fracture process of cell walls in the mesoscopic scale, obtained from in situ compression tests in SEM. The SEM images are shown at different loading stages indicated by the numbers 1-9 corresponding to the stressstrain curve. The arrow $\square$ indicates the regions where buckling begins, and arrow indicates the regions where fractures or contacts take place. The engineering strains $\varepsilon_{\mathrm{E}}$ from 1 to 9 are $10 \%, 15 \%, 20 \%, 30 \%, 35 \%, 40 \%, 50 \%, 60 \%$ and $75 \%$, respectively. 
Stage $1,10 \%$
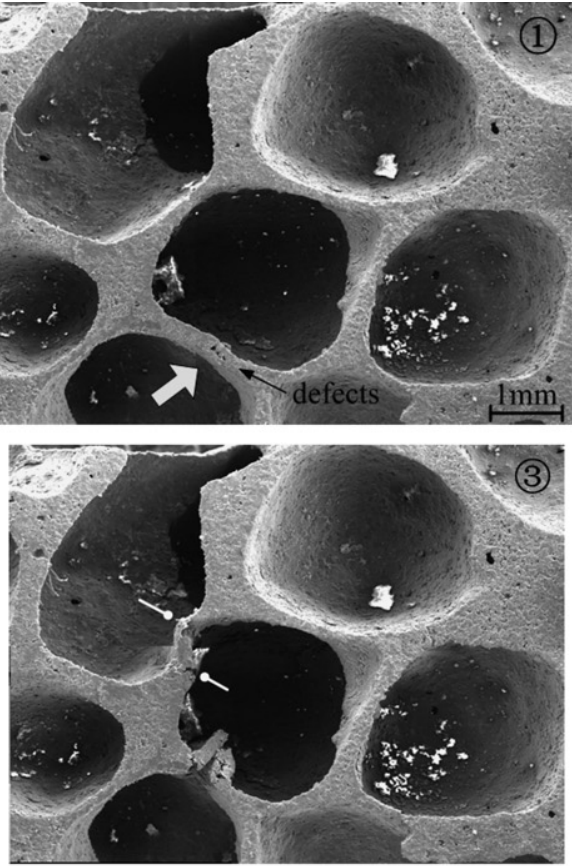

Stage $3,20 \%$

Stage $5,35 \%$

Stage $7,50 \%$

Stage $9,75 \%$
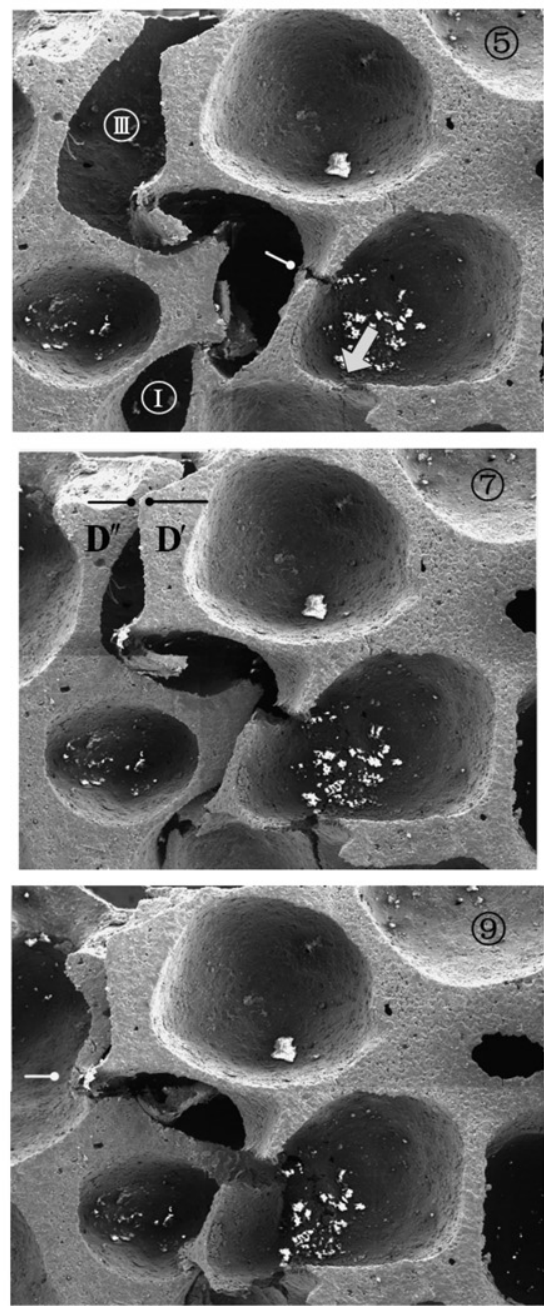
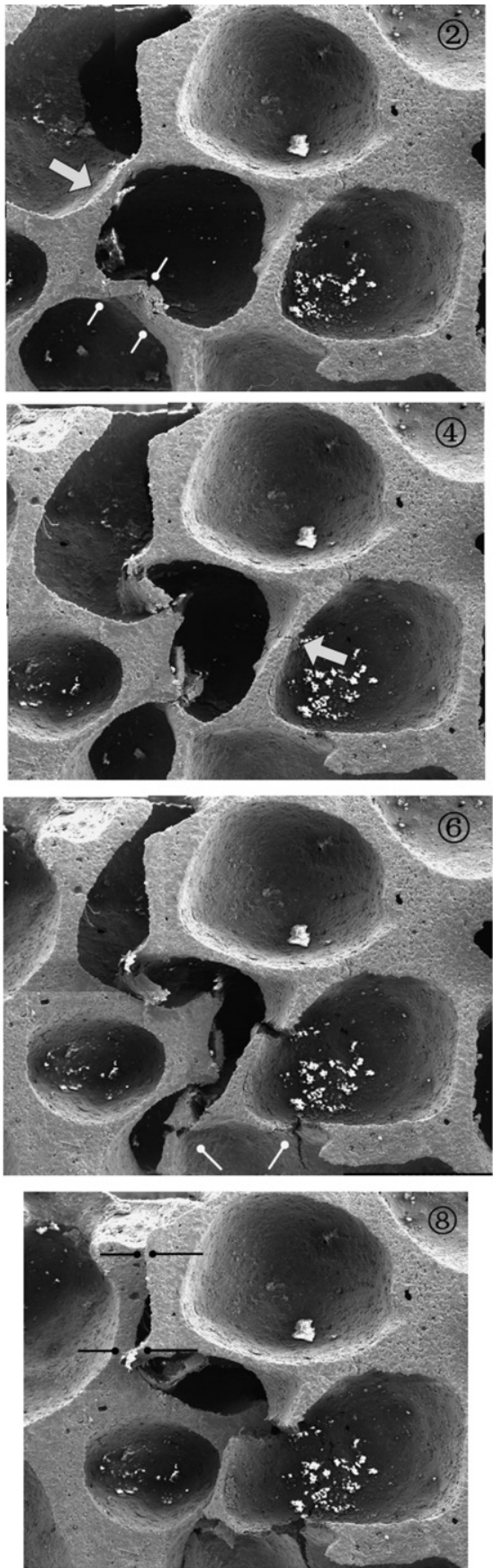

Stage $2,15 \%$

Stage $4,30 \%$

Stage $6,40 \%$

Stage $8,60 \%$

Fig. 6 (continued)

the cell walls; plateau regime, where the stress remains nearly constant with increasing deformation, accompanied by the initiation and propagation of fracture bands; and densification regime, where the stress rises steeply at high strains, accompanied by the sufficient collapse of cell walls and pack-together of broken fragments. 

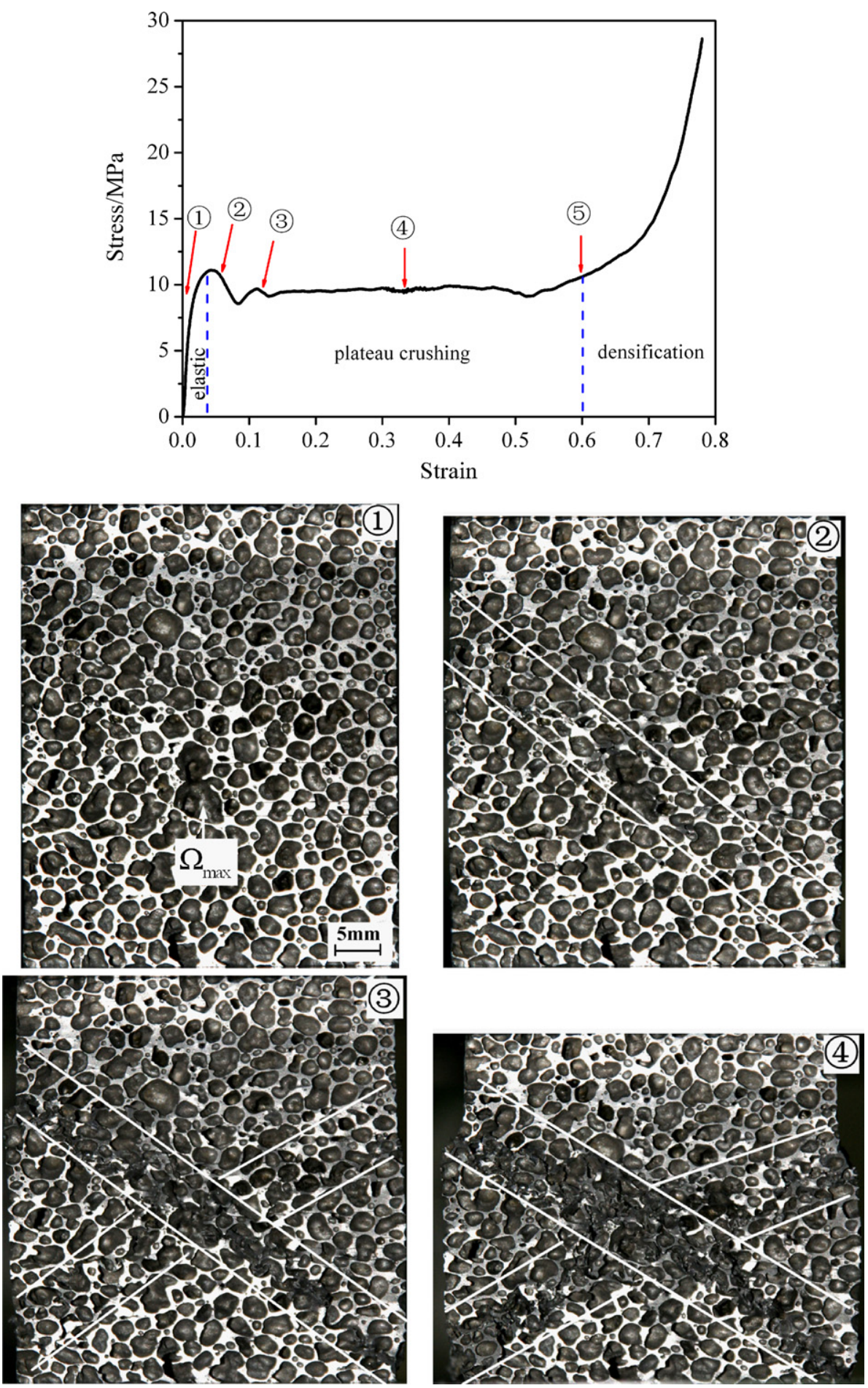

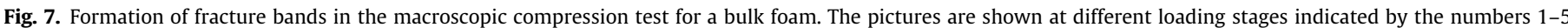
corresponding to the stress-strain curve. The engineering strains $\varepsilon_{\mathrm{E}}$ from 1 to 5 are $0,5.6 \%, 11.7 \%, 33.3 \%$ and $60 \%$, respectively.

In Fig. 7, the largest cell (marked $\Omega_{\max }$ ) is located near the center of the visible face. It has been reported that the permanent deformation or fracture starts predominantly in the regions with the highest concentration of defects and the lowest local densities [17-20], and regions with these characteristics are usually occupied by the largest cells. In the case shown in Fig. 7, cracks and fractures in the cell walls were first spotted in the cell $\Omega_{\max }$. As the compressive strain increased, two macroscopic fracture bands formed sequentially, both passing through $\Omega_{\max }$. The first fracture band became evident at the engineering strain $\varepsilon_{\mathrm{E}}$ of about $5.6 \%$ (stage 2). When further deforming of this band became difficult, the second fracture band came into being, at $\varepsilon_{\mathrm{E}}$ of about $11.7 \%$ (stage 3 ). When $\varepsilon_{\mathrm{E}}$ reached $33.3 \%$ (stage 4 ), two macroscopic fracture bands, swallowing most of the fractured cells, appeared vividly in a "X" shape. Similar to those in meso tests, the band normals are not coincident with the loading direction. Bastawros et al. [15] reported that for closed-cell Al alloy foams the angles between normals of deformation bands and the loading axis are usually within $20^{\circ}$, but in some instances reach $40^{\circ}$. Large angles (about $40^{\circ}$ ) were also observed in the present study. Notice that 
the in-plane crushing of honeycombs also produces oblique " $\mathrm{X}$ " shaped bands at low impact velocity [34]. According to the meso tests, local failure always results in stress redistribution, which means prominent stress concentration in the neighbouring cells or cell walls. Therefore, the subsequent failures often occur in the weakest cell walls of the neighbouring cells. All the fractured neighbouring cells formed the macroscopic fracture bands.

\subsection{Mesoscopic mechanisms of energy absorption}

Energy absorption, when evaluated quantitatively, can be obtained by integration of the load and displacement curve; when explained from the deformation mechanisms, can be any motion involved in the plastic yield or brittle fracture that leads to the variation in load-displacement responses. Bastawros et al. [15] suggested that the combination of distortional and rotational deformations produces at least three possible mechanisms at the cell-level. In the present study, special attention was paid to the failure modes of cell walls, in order to understand the mechanisms of energy absorption in the mesoscopic scale.

It has been well summarized that the dominating deformation mechanisms of the closed-cell foams were bending of cell edges and stretching of cell faces [24,35-37]. For ductile foams, cell walls usually deformed into plastic hinges at sufficiently high loads, and bending and hinging are the main mechanisms. The images ac-
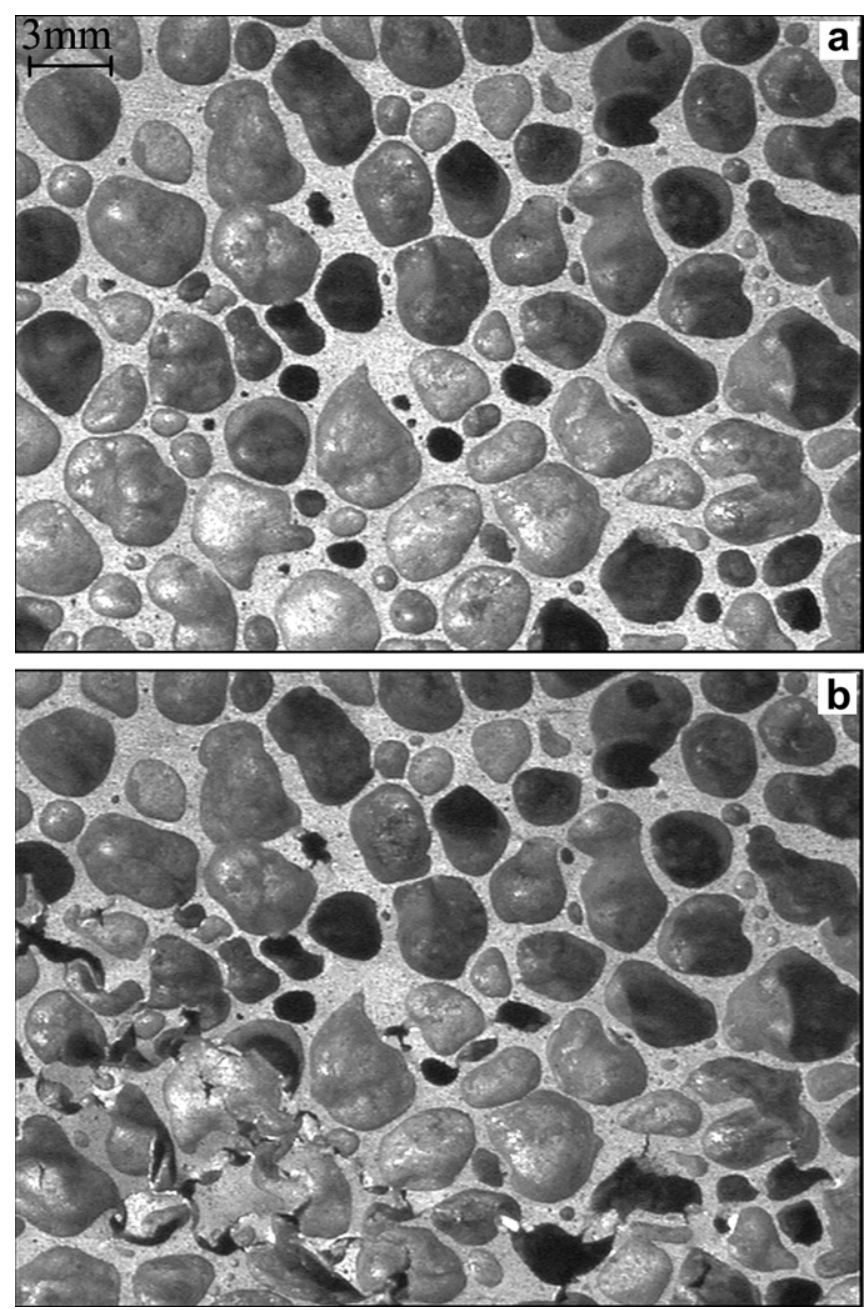

Fig. 8. Images acquired from $C C D$, showing various failure modes in cells and cell walls in brittle foams. (a) As received. (b) After $\varepsilon_{\mathrm{E}}=20 \%$. Apart from a macroscopic fracture band, individual cells experience various failure modes before being "swallowed" by the fracture bands.
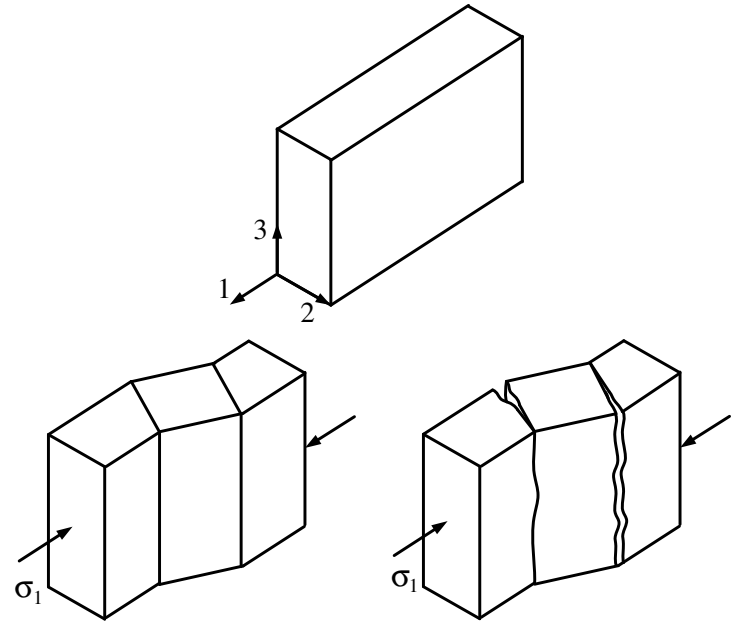

(a) Mode I

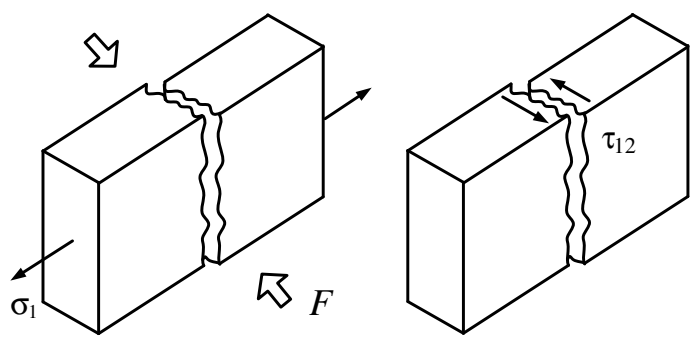

(b) Mode II

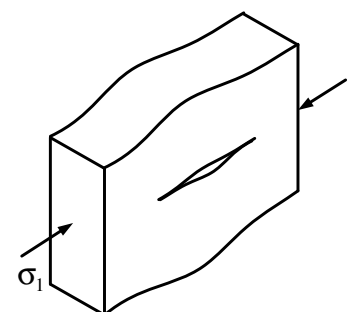

(c) Mode III

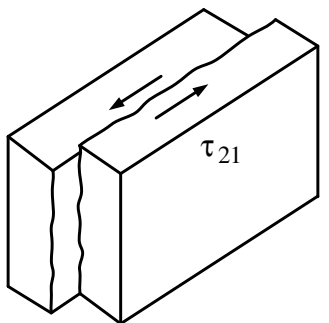

(d) Mode IV
Fig. 9. Failure modes in the cell-wall level, in order to understand the energy absorption mechanisms in the mesoscopic scale. (a) Mode I; (b) Mode II; (c) Mode III; (d) Mode IV.

quired from CCD in Fig. 8 however, show more complex failure modes in cells and cell walls for brittle closed-cell foams. When considered at the cell-wall level, at least four failure modes can be identified. The sketches of the basic failure modes were illustrated in Fig. 9. Mode I is compressive bending and fracturing. At low strains, the cell wall begins to yield and bend, forming either one, two or three "hinges". This early stage behavior is similar to the plastic deformation of ductile foams. At high strains, the cell wall eventually fractures at the hinge positions into several fragments. Mode II is direct brittle fracture due to tension or shearing. Tensile or shear stress can be induced in the cell walls nearly perpendicular to the compression axis, by stretching the cell faces. Mode III is cracking in the cell face, due to stretching induced from remote compressive stress, when the cell face parallels the compression axis. Mode IV is shear and friction between fractured cell walls, usually occurs at high compressive strains. The above phenomenological description of failure modes were summarized from the in situ observation of compression tests for mesoscopic samples. Fig. 10 gives some typical SEM images corresponding to the failure modes descrpted in Fig. 9. The major mechanisms of energy absorption in the mesoscopic scale are those comprised in 

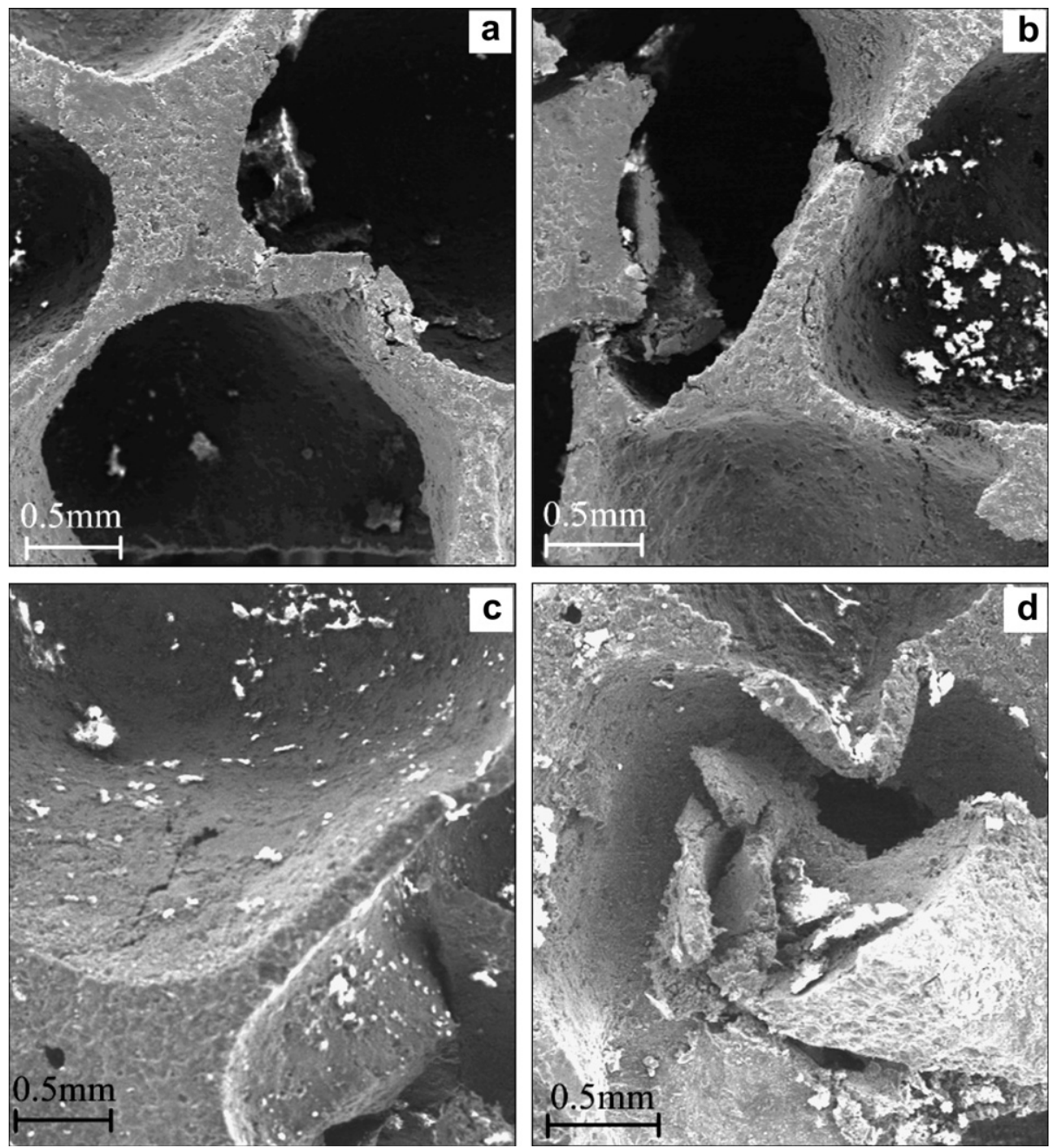

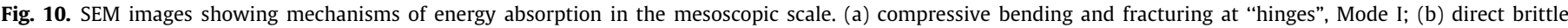
fracturing due to induced tension or shear, Mode II; (c) cracking in the cell face, Mode III; (d) friction and shear between fractured cells, Mode IV.

Modes I, II and III, all of which lead to fractures in cell walls. Fracture energy is usually higher than plastic energy at a given deformation, that is the reason why typically brittle foams absorb more energy than ductile ones in the condition of progressive compression.

\subsection{Mechanical properties: size effect}

In the present study, both types of specimens are in some extreme conditions. The edges of the ETZ in mesoscopic samples and the edges of macroscopic samples are approximately 1.5 and 15 times of the average cell size, respectively. The mechanical properties obtained from these tests involve strong size effect. According to the size-effect models for ductile cellular solids proposed by Onck et al. [24], for a square-prism foam with the cross section of $\alpha d \times \alpha d$ (where $d$ is the average cell size, $\alpha$ is the cell number contained in one edge), the Young's modulus $E_{\mathrm{pl}}$ gives

$\frac{E_{\mathrm{pl}}}{E^{*}}=\left(1-\frac{2 n}{\alpha}-\frac{2 p}{\alpha}\right)^{2}+\frac{4 m n}{\alpha}\left(1-\frac{2 n}{\alpha}-\frac{2 p}{\alpha}\right)+\frac{4 m^{2} n^{2}}{\alpha^{2}}$

where $E^{*}$ is the true Young's modulus obtained from bulk materials with sufficient large dimensions, $m$ is the reduced stiffness factor for the boundary layer of thickness $n d$ and the stress free layer of zero stiffness is of thickness pd. Reference [25] gave a demonstration plot according to Eq. (2) with $m=0.85, n=0.5$ and $p=0.25$. The plastic collapse strength $\sigma_{\mathrm{pl}}$ obeys $\frac{\sigma_{\mathrm{pl}}}{\sigma_{\mathrm{pl}}^{*}}=\frac{\left(\alpha-\frac{1}{2}\right)^{2}}{\alpha^{2}}$

where $\sigma_{\mathrm{pl}}^{*}$ is the true plastic collapse strength obtained from specimens of sufficient large. For the brittle metallic foams, the above two size-effect equations may also feasible. Blazy et al. [38] reported that metallic foams usually deforms in a combination of brittle fracture and plastic yielding, and they did not make distinction of these two mechanisms. Although the AlSi12 foams are typical brittle materials [19], at the early stage of deformation they behave like ductile metallic foams, as depicted in the previous section. For the meso tests, $\alpha$ is among $1.5-2$, therefore $E_{\mathrm{pl} 1}=0.32-0.46 E^{*}$, $\sigma_{\mathrm{pl} 1}=0.44 \sim 0.56 \sigma_{\mathrm{pl}}^{*}$. As for the macro tests, $\alpha=15$, therefore $E_{\mathrm{pl} 2}=0.92 E^{*}, \sigma_{\mathrm{pl} 2}=0.93 \sigma_{\mathrm{pl}}^{*}$. The mechanical properties obtained from macro tests approximate to the true values. The predicted ratios of the two type tests are, $E_{\mathrm{pl} 1} / E_{\mathrm{pl} 2}=0.35-0.5 \mathrm{E} 8$ and $\sigma_{\mathrm{pl} 1} /$ $\sigma_{\mathrm{pl} 2}=0.47-0.6$, respectively.

The true Young's modulus $\mathrm{E}^{*}$ and true plastic strength $\sigma_{\mathrm{pl}}^{*}$ can be predicted from the models proposed by Gibson and Ashby [12]. Neglected the gas pressure effect, the brittle closed-cell foams have

$$
\begin{aligned}
& \frac{E^{*}}{E_{\mathrm{s}}}=\phi^{2}\left(\frac{\rho^{*}}{\rho_{\mathrm{s}}}\right)^{2}+(1-\phi)\left(\frac{\rho^{*}}{\rho_{\mathrm{s}}}\right) \\
& \frac{\sigma_{\mathrm{pl}}^{*}}{\sigma_{\mathrm{ys}}}=0.2\left(\phi \frac{\rho^{*}}{\rho_{\mathrm{s}}}\right)^{3 / 2}+(1-\phi) \frac{\rho^{*}}{\rho_{\mathrm{s}}}
\end{aligned}
$$


Table 1

Comparison of mechanical properties: macro and meso, experimental and theoretical

\begin{tabular}{|c|c|c|c|c|c|c|}
\hline & $\begin{array}{l}\text { Macro, prediction } \\
(\mathrm{MPa})\end{array}$ & $\begin{array}{l}\text { Meso, prediction } \\
(\mathrm{MPa})\end{array}$ & $\begin{array}{l}\text { Predicted ratio (meso/ } \\
\text { macro) }\end{array}$ & $\begin{array}{l}\text { Macro, experiments } \\
\text { (MPa) }\end{array}$ & $\begin{array}{l}\text { Meso, experiments } \\
\text { (MPa) }\end{array}$ & $\begin{array}{l}\text { experimental ratio (meso/ } \\
\text { macro) }\end{array}$ \\
\hline $\begin{array}{l}\text { Young's } \\
\text { modulus E }\end{array}$ & 10304 & $3584-5152$ & $0.35-0.5$ & 672.0 & 61.8 & $0.09(0.3)$ \\
\hline $\begin{array}{l}\text { Plastic strength } \\
\qquad \sigma_{\mathrm{pl}}\end{array}$ & 22.2 & $10.6-13.4$ & $0.47-0.6$ & 10.3 & 6.0 & 0.58 \\
\hline
\end{tabular}

where $\phi$ is the volume fraction of solid in the foam that is contained in cell edges, $E_{\mathrm{s}}$ and $\sigma_{\mathrm{ys}}$ are the Young's modulus and yield stress of cell wall material respectively, $\rho^{*} / \rho_{\mathrm{s}}$ is the relative density of the foam. Predictions of Young's modulus and plastic collapse strength in Eqs. (4) and (5) require data for cell wall modulus $E_{\mathrm{s}}$, yield stress $\sigma_{\mathrm{ys}}$ and relative density. For the AlSi12 foam of NEU brand, we took $E_{\mathrm{s}}=70 \mathrm{GPa}, \sigma_{\mathrm{ys}}=157 \mathrm{MPa}$, the relative density $\rho^{*} / \rho_{\mathrm{s}}=0.25$, and $\phi$ $=0.4$. Combining Eqs. (2)-(5), one obtains the predicted Young's modulus $E_{\mathrm{pl}}$ and plastic strength $\sigma_{\mathrm{pl}}$ for both meso and macro specimens. The predicted values are compared with those of tests, which were obtained by averaging the data of at least three typical samples. Table 1 gives the results. The obvious discrepancies of absolute values between predictions and experiments are caused by morphological defects in the microstructures of the foams, the effects which were not included in the Gibson and Ashby's models $[39,40]$. The ratios of plastic strengths are in a reasonable accordance in predictions and experiments, indicating a good match of size-effect models proposed by Onck et al. [24]. Apparently the elastic modulus obtained from meso tests underestimated the value by neglecting elastic deformation outside ETZ. Inclusion the elastic behaviour outside ETZ, the ratio of Young's moduli in meso and macro tests is raised from 0.09 to 0.38 , a value approaches the predicted ratio obtained from Eq. (2). The normalized Young's modules $E_{\mathrm{pl}} / E^{*}$ and normalized plastic strength $\sigma_{\mathrm{pl}} / \sigma^{*}$ plotted against normalized edge length $\alpha$, obtained both from models and experiments, are given in Fig. 11. In this figure, the true Young's modulus and plastic strength, $E^{*}$ and $\sigma_{\mathrm{pl}}^{*}$, were obtained from macro tests according to Eqs. (2) and (3), respectively. Commercial metallic foams invariably contain imperfections and inhomogeneities in their cell structures [16]. On the mesoscopic scale the morphological defects include missing cell wall, pores, plateau border, wiggle, etc. [39]. In the macro tests, each edge of the sample is at least 15 times the cell size, and the effects of local imperfections and boundary layers could be reduced to an acceptable level. In the meso tests, however,

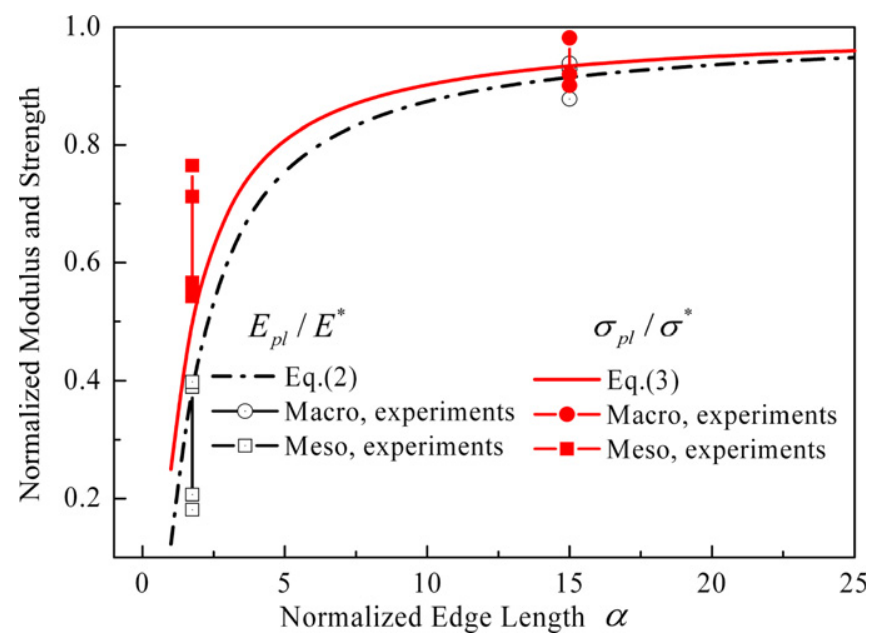

Fig. 11. Normalized Young's modules and plastic strength plotted against normalized edge length $\alpha$. local imperfections and morphology variance would be dominant. Fig. 11 shows the scattered mechanical properties obtained from meso tests, whereas those obtained from macro tests show little dispersion. While investigating the size effect on the compression strength of brittle graphitic foams, Mora and Waas [26] pointed out that the fewer amounts of struts present in the foam structure, the higher the non-uniformity of the critical stresses. They also plotted the critical stress against the loading area into three stages: discrete behaviour, transition phase and continuum behaviour. The discrete behaviour stage shows similar tendency to Fig. 11.

\section{Conclusions}

In situ tests for condensed materials inside the SEM can be readily found. For a material which is cellular structured macroscopically, i.e., the cell size is comparable to the specimen dimension that could be prepared for the inside-SEM examination (obtain the sequential deformation images and stress-strain responses simultaneously), this kind of in situ test is rare. Rather than to learn the actual stiffness or strength of the material, the main objective of in situ tests adopted in the present study is to correlated the instantaneous stress-strain responses with the fracture process of a single cell and its cell walls, therefore identify the mechanisms of energy absorption in the mesoscopic scale. The limited number of cell walls inside the ETZ that can sustain the compressive load, is helpful to achieve this goal. According to the in situ mesoscopic compression tests, four major failure modes in the cell-wall level were characterized. Mode I, compressive bending and fracturing at "hinges"; Mode II, direct brittle fracturing due to induced tension or shear; Mode III, cracking in the cell face; and Mode IV, friction and shear between fractured cells.

The study also made attempts to connect meso tests with macro tests. Although the local imperfections and variance in cell morphology may dominate the fracture process of a meso sample, the typical stress-strain curve can still be divided into three characteristic stages. Unlike marco tests, the stress-strain curve of a meso test has no plateau stress regime, instead the bending and fracturing regime demonstrates strong dispersion in the stress response. However, the mechanical properties obtained from the two types of tests can be generalized in the size-effect models. This means the size-effect models for ductile cellular solids proposed by Onck et al. [24] can be readily used for brittle metallic foams. As also observed by previous researchers, both fracturing of a single cell and cell walls in meso tests and developing of fracture bands in macro tests are defect-directed or weakness-directed processes.

The in situ meso compression test method employed in the present study is also helpful in characterizing the representative unit cell and its failure behaviours for metallic foams, therefore building the unit-cell-based models $[41,42]$. Further work may be carried out in this category.

\section{Acknowledgements}

Supports for this work from National Nature Science Foundation of China (No. 10502049) and Foundation of State Key 
Laboratory of Nonlinear Mechanics from Institute of Mechanics, Chinese Academy of Sciences, are gratefully acknowledged. The authors gratefully acknowledge the support of K.C. Wong Education Foundation, Hong Kong. The authors would also like to express their appreciation to Dr. Xiaoming Zhang in Northeastern University of China, for providing the foam materials.

\section{References}

[1] Seitzberger M, Rammerstorfer FG, Degischer HP, Gradinger R. Crushing of axially compressed steel tubes filled with aluminium foam. Acta Mechanica 1997; 125(1-4):93.

[2] Hanssen AG, Langseth M, Hopperstad OS. Static crushing of square aluminium extrusions with aluminium foam filler. Int J Mech Sci 1999;41(8):967.

[3] Santosa SP, Wierzbicki T, Hanssen AG, Langseth M. Experimental and numerical studies of foam-filled sections. Int J Impact Eng 2000;24(5):509.

[4] Chen WG. Experimental and numerical study on bending collapse of aluminum foam-filled hat profiles. Int J Solid Struct 2001;38(44-45):7919.

[5] Hanssen AG, Langseth M, Hopperstad OS. Optimum design for energy absorption of square aluminium columns with aluminium foam filler. Int $\mathrm{J}$ Mech Sci 2001;43(1):153.

[6] Song HW, Fan ZH, Yu G, Wang QC, Tobota A. Partition energy absorption of axially crushed aluminum foam-filled hat sections. Int J Solid Struct 2005;42( 9-10):2575.

[7] McCormack TM, Miller R, Kesler O, Gibson LJ. Failure of sandwich beams with metallic foam cores. Int J Solid Struct 2001;38(28-29):4901.

[8] Chen C, Harte AM, Fleck NA. The plastic collapse of sandwich beams with a metallic foam core. Int J Mech Sci 2001;43(6):1483.

[9] Kesler O, Gibson LJ. Size effects in metallic foam core sandwich beams. Mater Sci Eng A - Struct Mater Prop Microstruct Process 2002;326(2):228.

[10] Bart-Smith H, Hutchinson JW, Fleck NA, Evans AG. Influence of imperfections on the performance of metal foam core sandwich panels. Int J Solid Struct 2002;39(19):4999.

[11] Crupi V, Montanini R. Aluminium foam sandwiches collapse modes under static and dynamic three-point bending. Int J Impact Eng 2007;34(3):509.

[12] Gibson LJ, Ashby MF. Cellular solids: structures and properties. UK, Cambridge: Cambridge Univ. Press; 1997.

[13] Gradinger R, Rammerstorfer FG. On the influence of meso-inhomogeneities on the crush worthiness of metal foams. Acta Materialia 1998;47(1):143.

[14] Daxner T, Bohm HJ, Rammerstorfer FG. Mesoscopic simulation of inhomogeneous metallic foams with respect to energy absorption. Comput Mater Sci 1999;16(1-4):61.

[15] Bastawros AF, Bart-Smith H, Evans AG. Experimental analysis of deformation mechanisms in a closed-cell aluminum alloy foam. J Mech Phys Solid 2000;48(2):301.

[16] Markaki AE, Clyne TW. The effect of cell wall microstructure on the deformation and fracture of aluminium-based foams. Acta Materialia 2001;49(9):1677.

[17] Maire E, Babout L, Buffiere JY, Fougeres R. Recent results on 3D characterisation of microstructure and damage of metal matrix composites and a metallic foam using X-ray. Mater Sci Eng A - Struct Mater Prop Microstruct Process 2001;319:216.

[18] Elmoutaouakkil A, Salvo L, Maire E, Peix G. 2D and 3D characterization of metal foams using X-ray tomography. Adv Eng Mater 2002;4(10):803.
[19] San Marchi C, Despois JF, Mortensen A. Uniaxial deformation of open-cell aluminum foam: the role of internal damage. Acta Materialia 2004;5(10):2895.

[20] McDonald SA, Mummery PM, Johnson G, Withers PJ. Characterization of the three-dimensional structure of a metallic foam during compressive deformation. J Microscopy-Oxford 2006;223:150.

[21] Zhou J, Shrotriya P, Soboyejo WO. Mechanisms and mechanics of compressive deformation in open-cell Al foams. Mech Mater 2004;36(8):781.

[22] Motz C, Pippan R. Fracture behaviour and fracture toughness of ductile closedcell metallic foams. Acta Materialia 2002;50(8):2013.

[23] Maire E, Fazekas A, Salvo L, et al. X-ray tomography applied to the characterization of cellular materials. Related finite element modeling problems. Compos Sci Technol 2003;63:2431.

[24] Onck PR, Andrews EW, Gibson LJ. Size effects in ductile cellular solids. Part I: modeling. Int J Mech Sci 2001;43(3):681.

[25] Andrews EW, Gioux G, Onck P, Gibson LJ. Size effects in ductile cellular solids. Part II: experimental results. Int J Mech Sci 2001;43(3):701.

[26] Mora RJ, Waas AM. Strength scaling of brittle graphitic foam. Proc Royal Soc London A - Math Phys Eng Sci 2002:458(2023):1695.

[27] Chen C, Fleck NA. Size effects in the constrained deformation of metallic foams. J Mech Phys Solid 2002;50(5):955.

[28] Rakow JF, Waas AM. Size effects in metal foam cores for sandwich structures Aiaa J 2004;42(7):1331.

[29] Rakow JF, Waas AM. Size effects and the shear response of aluminum foam. Mech Mater 2005;37(1):69.

[30] Yu H, Yao G, Wang X, Liu Y, Li H. Sound insulation property of A1-Si closed-cell aluminum foam sandwich panels. Appl Acoust 2007;68(11-12):1502.

[31] Deshpande VS, Fleck NA. Isotropic constitutive models for metallic foams. J Mech Phys Solid 2000;48(6-7):1253.

[32] Motz C, Pippan R. Deformation behaviour of closed-cell aluminium foams in tension. Acta Materialia 2001;49(13):2463.

[33] Beals JT, Thompson MS. Density gradient effects on aluminium foam compression behaviour. J Mater Sci 1997;32(13):3595.

[34] Ruan D, Lu G, Wang B, Yu TX. In-plane dynamic crushing of honeycombs - a finite element study. Int J Impact Eng 2003;28(2):161.

[35] Andrews E, Sanders W, Gibson LJ. Compressive and tensile behaviour of aluminum foams. Mater Sci Eng A - Struct Mater Prop Microstruct Process 1999;270(2):113.

[36] Simone AE, Gibson LJ. The effects of cell face curvature and corrugations on the stiffness and strength of metallic foams. Acta Materialia 1998;46(11):3929.

[37] Chen C, Lu TJ, Fleck NA. Effect of imperfections on the yielding of twodimensional foams. J Mech Phys Solid 1999;47(11):2235

[38] Blazy JS, Marie-Louise A, Forest S, Chastel Y, Pineau A, Awade A, et al. Deformation and fracture of aluminium foams under proportional and non proportional multi-axial loading: statistical analysis and size effect. Int J Mech Sci 2004:46(2):217.

[39] Ramamurty U, Paul A. Variability in mechanical properties of a metal foam. Acta Materialia 2004;52(4):869.

[40] Olurin OB, Fleck NA, Ashby MF. Deformation and fracture of aluminium foams Mater Sci Eng A - Struct Mater Prop Microstruct Process 2000;291(1-2):136.

[41] Santosa S, Wierzbicki T. On the modeling of crush behavior of a closed-cell aluminum foam structure. J Mech Phys Solid 1998;46(4):645.

[42] Czekanski A, Attia MS, Meguid SA, Elbestawi MA. On the use of a new cell to model geometric asymmetry of metallic foams. Finite Element Anal Design 2005;41(13):1327. 